\title{
Blue-Emitting Heteroleptic Iridium(III) Complexes Suitable for High-Efficiency Phosphorescent OLEDs**
}

\author{
Cheng-Han Yang, Yi-Ming Cheng, Yun Chi, *Chia-Jung Hsu, Fu-Chuan Fang, Ken-Tsung Wong, \\ Pi-Tai Chou, * Chih-Hao Chang, Ming-Han Tsai, and Chung-Chih Wu*
}

Phosphorescent OLEDs are under intense investigation because of their potential in greatly improving device performances. ${ }^{[1]}$ Electrophosphorescence is easily generated from both singlet and triplet excited states so the internal quantum efficiency of phosphorescent organic light-emitting diodes (OLEDs) can reach a theoretical level of unity, rather than the inherent $25 \%$ upper limit imposed by the formation of singlet excitons for their fluorescent counterparts. ${ }^{[2]}$ Thus, a great deal of effort has been spent investigating the third-row transition-metal complexes to develop highly efficient phosphors that can emit all three primary colors. Despite elegant research on both red and green phosphors, there are only a few reports on room-temperature blue phosphors. ${ }^{[3]}$ Two wellunderstood examples, bis(4',6'-difluorophenylpyridinato)iridium(III) picolinate (FIrpic) and bis $\left(4^{\prime}, 6^{\prime}\right.$-difluorophenylpyridinato)iridium(III) tetra(1-pyrazolyl)borate (FIr6), have proven to be excellent dopants for greenishblue and sky-blue phosphorescent OLEDs. ${ }^{[4]}$ Further improvements were made by substituting the picolinate ions with other ancillary ligands, such as triazolate or tetrazolate ions to give FIrtaz or FIrN4, respectively, ${ }^{[5]}$ and even by employing a combination of cyanide and phosphine ligands. ${ }^{[6]}$ These modifications have produced a hypsochromic shift of around $10 \mathrm{~nm}$ compared to the emission of FIrpic. However, significant lowering of emission quantum yield was noted in

[*] C.-H. Yang, Dr. Y.-M. Cheng, Prof. Y. Chi

Department of Chemistry

National Tsing Hua University

Hsinchu 300 (Taiwan)

Fax: $(+886)$ 3-572-0864

E-mail:ychi@mx.nthu.edu.tw

C.-J. Hsu, F.-C. Fang, Prof. K.-T. Wong, Prof. P.-T. Chou

Department of Chemistry

National Taiwan University

Taipei 106 (Taiwan)

Fax: $(+886)$ 2-2369-5208

E-mail:chop@ntu.edu.tw

C.-H. Chang, M.-H. Tsai, Prof. C.-C. Wu

Department of Electrical Engineering and

Graduate Institute of Electro-optical Engineering

National Taiwan University

Taipei 106 (Taiwan)

Fax: $(+886)$ 2-2367-1909

E-mail: chungwu@cc.ee.ntu.edu.tw

$[\cdots *$ This work was supported by the National Science Council and Ministry of Economic Affairs of Taiwan; OLEDs is organic lightemitting diodes.

0 Supporting information for this article is available on the WWW under http://www.angewandte.org or from the author.

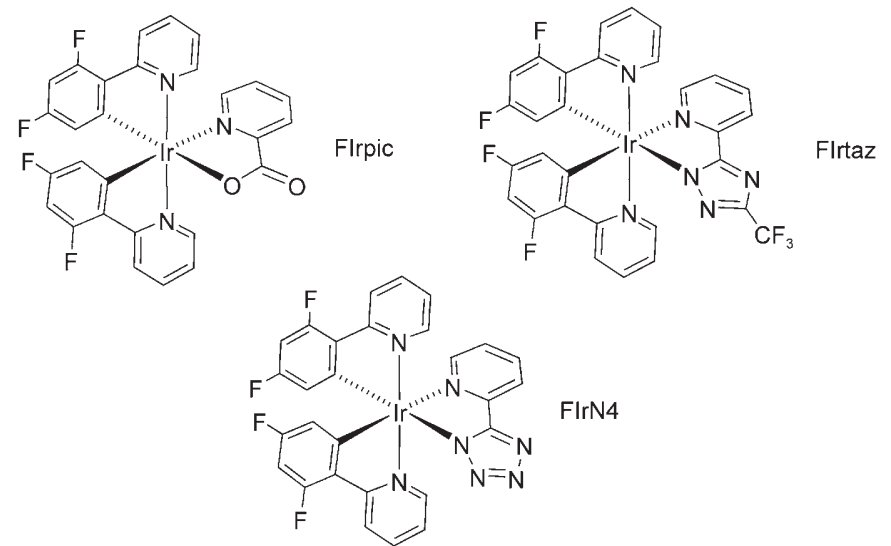

some cases, which has hampered the fabrication of true-blue phosphorescent OLEDs.

In theory, some critical criteria have to be considered in obtaining highly efficient blue phosphorescence. Of primary importance is to increase the contribution of the metal-toligand charge transfer (MLCT) in the lowest-lying triplet manifold. ${ }^{[7]}$ The direct involvement of the metal $\mathrm{d}_{\pi}$ orbital enhances the coupling of the orbital angular momenta to the electron spin, such that the $\mathrm{T}_{1} \rightarrow \mathrm{S}_{0}$ transition would have a large first-order spin-orbit coupling term, which would result in a drastic decrease in the radiative lifetime and hence the possibility of increasing the quantum yield.

Conversely, care has to be taken to avoid enhanced radiationless pathways arising from enlargement of the band gap. One familiar deactivation pathway lies in the $d-d$ transition, which may weaken the metal-ligand bond, thus resulting in a shallow potential-energy surface. ${ }^{[8]}$ In an extreme case, the shallow $\mathrm{d}-\mathrm{d}$ potential-energy surface may intercept surfaces of other states, which may result in radiationless deactivation. This process, however, should be minor for third-row transition metals owing to their high coordination strength that increases the energy of the $d_{\sigma^{*}}$ orbitals. ${ }^{[9]}$ Furthermore, upon increasing the energy gap towards blue, it becomes facile for the lowest-lying excited state - a state perhaps comprising both $\pi-\pi^{*}$ (or intraligand charge transfer, ILCT) and MLCT in character-to mix with a thermally accessible ligand-to-ligand charge-transfer (LLCT) state. ${ }^{[10]}$ Mixing with the LLCT state may increase the radiative lifetime owing to the largely charge-separated character of this state and hence the probability of a partially forbidden transition (versus the ground state). The net result is a reduction in the corresponding emission quantum yield if similar deactivation mechanisms operate.

In our view, the above scenario may be avoided by selecting facially arranged homoleptic complexes or by using 
a heteroleptic coordination arrangement, for which the excitation is equally spread among the degenerate states of multiple chromophores or restrains to a single chromophore. ${ }^{[11]}$ Delocalization of the electron density not only stabilizes the molecular framework but also reduces the radiationless deactivation processes because of the resulting steeper potential-energy surfaces. Herein, we report the characterization of two isomeric $\mathrm{Ir}^{\mathrm{III}}$ complexes in anticipation of seeing the phenomenon that would confirm the above theories and show efficient blue phosphorescence with better chromaticity.

The preparation of the isomeric iridium complexes [Ir(dfppy)(fppz) $)_{2}$ (dfppyH: 2-(2,4-difluorophenyl)pyridine, fppzH: 5-(2-pyridyl)-3-trifluoromethylpyrazole) (1) and (2) was best executed by heating of a 1:1 mixture of (dfppy) $\mathrm{H}$ and $\mathrm{IrCl}_{3} \cdot 3 \mathrm{H}_{2} \mathrm{O}$ in methoxyethanol $\left(140^{\circ} \mathrm{C}, 4 \mathrm{~h}\right)$ with subsequent

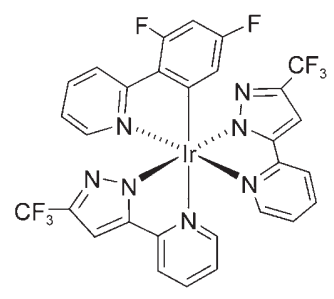

1

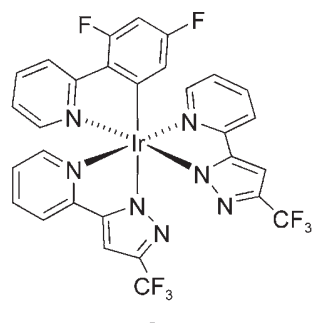

2

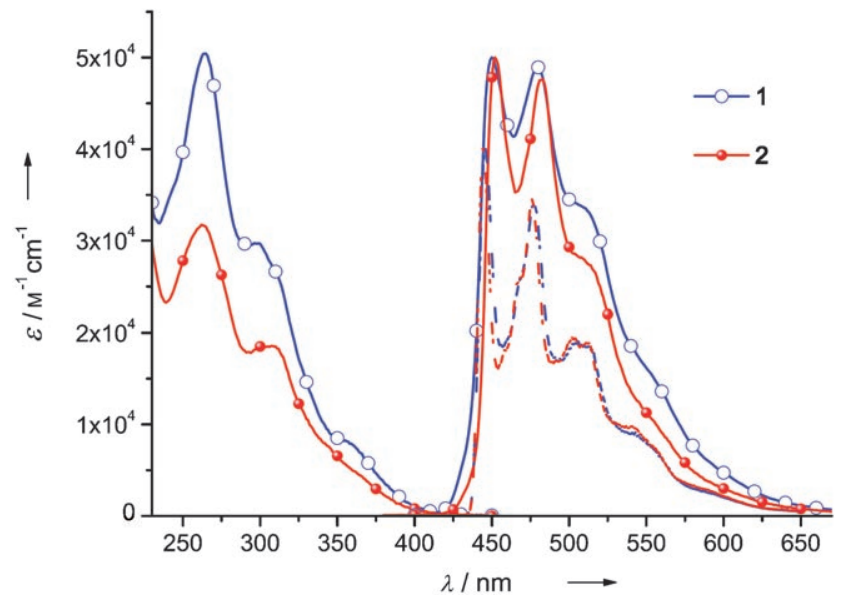

Figure 1. Absorption and luminescence spectra of $\mathbf{1}$ and $\mathbf{2}$ in degassed $\mathrm{CH}_{2} \mathrm{Cl}_{2}$ at room temperature; dotted lines indicate emissions recorded in a $\mathrm{CH}_{2} \mathrm{Cl}_{2}$ matrix frozen at $77 \mathrm{~K}$.

section is significant, especially in the ligand ${ }^{1} \pi-\pi^{*}$ $(\leq 300 \mathrm{~nm})$ transition, as a consequence of the different ligand orientations of complexes $\mathbf{1}$ and $\mathbf{2}$. With regard to emission properties, complex $\mathbf{1}$ in a degassed solution of $\mathrm{CH}_{2} \mathrm{Cl}_{2}$ at $298 \mathrm{~K}$ exhibited strong phosphorescence with a quantum yield of 0.50 , for which four vibronic peaks

addition of 2.1 equivalents of $(\mathrm{fppz}) \mathrm{H}$ in the presence of $\mathrm{Na}_{2} \mathrm{CO}_{3}\left(140^{\circ} \mathrm{C}, 8 \mathrm{~h}\right)$. This synthetic logic relies on the prior generation of an intermediate of hypothetical formula [(dfppy) $\left.\mathrm{IrCl}_{2}\right]_{x}$, which would react with fppz anions in the subsequent reaction. Moreover, heating a diethyl glycol monoethyl ether so-

Table 1: Photophysical data of $\mathrm{Ir}^{\mathrm{III}}$ complexes $\mathbf{1}$ and $\mathbf{2}$ (unless otherwise specified, the decay of emission was monitored at $450 \mathrm{~nm}$ for the relaxation dynamics $\left.\left(\lambda_{\mathrm{exc}}=350 \mathrm{~nm}\right)\right)$.

\begin{tabular}{|c|c|c|c|c|c|}
\hline & $\left.\varepsilon \times 10^{-3}\left[\mathrm{M}^{-1} \mathrm{~cm}^{-1}\right]\right)$ & $\lambda_{\operatorname{maxem} .}[\mathrm{nmm}]^{[\mathrm{a}]}$ & Q.Y. & $\tau_{\text {obs }}[\mu \mathrm{s}]$ & $\tau_{\mathrm{r}}[\mu \mathrm{s}]$ \\
\hline 1 & $\begin{array}{l}264(50.4), 299(29.7), 311(26.3), 326 \\
(16.7) 356(8.2)\end{array}$ & $\begin{array}{l}450,479,511( \\
554(\mathrm{sh})\end{array}$ & $\begin{array}{l}0.50^{[a]} \\
0.45^{[c]}\end{array}$ & $\begin{array}{l}3.8^{[a]} 6.7,{ }^{[b]} \\
0.4(78 \%), 1.2(22 \%)^{[c]}\end{array}$ & $7.7^{[a]}$ \\
\hline 2 & $\begin{array}{l}263(31.7), 306(18.5), 326(11.9) 357 \\
(5.5)\end{array}$ & $\begin{array}{l}450,480,515(\mathrm{sh}) \\
545 \text { (sh) }\end{array}$ & $\begin{array}{l}0.14^{[a]} \\
0.28^{[c]}\end{array}$ & $\begin{array}{l}4.4{ }^{[a]} 8.2,{ }^{[b]} \\
0.1(88 \%), 1.3(12 \%)^{[c]}\end{array}$ & $31.1^{[a]}$ \\
\hline
\end{tabular}

[a] Obtained from samples in degassed $\mathrm{CH}_{2} \mathrm{Cl}_{2}$. [b] Obtained from samples at $77 \mathrm{~K}$ in a $\mathrm{CH}_{2} \mathrm{Cl}_{2}$ matrix. [c] Obtained from samples in a doped thin film by using $\mathrm{CzSi}$ as the host material.

lution of $\mathbf{2}$ at reflux for $4 \mathrm{~h}$ yielded

the strongly emissive isomer $\mathbf{1}$ in $42 \%$ yield, thus confirming its nature as the thermodynamic product.

Single-crystal X-ray crystallography was carried out to differentiate the molecular structures of the two isomers (see Figure S1 and S2 of the Supporting Information). ${ }^{[12]}$ Both complexes have a slightly distorted octahedral geometry with one cyclometalated dfppy ligand and two chelating fppz ligands. They differ in the functional group of both fppz ligands that is located trans to the dfppy ligand: the pyridyl group in $\mathbf{1}$ and the pyrazolyl group in $\mathbf{2}$. Moreover, the $\mathrm{Ir}-\mathrm{N}$ bond that lies opposite the Ir-C bond (2.157(10) $\AA$ in $\mathbf{1}$ and $2.100(8) \AA$ in 2 ) is significantly longer than other $\operatorname{Ir}-\mathrm{N}$ bonds (2.028-2.063 $\AA$ in $\mathbf{1}$ and 1.997-2.075 $\AA$ in 2). This observation confirms the anticipated trans effect imposed by the morecovalent $\mathrm{Ir}-\mathrm{C}$ bonding in this class of $\mathrm{Ir}^{\mathrm{III}}$ complexes. ${ }^{[13]}$

Next we realized a remarkable difference in the photophysical behavior of $\mathbf{1}$ and $\mathbf{2}$. Figure 1 shows the UV/Vis absorption and emission spectra of both $\mathbf{1}$ and $\mathbf{2}$ in $\mathrm{CH}_{2} \mathrm{Cl}_{2}$ (see also Table 1). In general, the lower-lying absorption band (shoulder) with peak wavelengths at $345-355 \mathrm{~nm}$ can be reasonably assigned to a mixed $\pi-\pi^{*}$ and MLCT transition (see below). Note that the difference in the absorption cross correspond to approximately $450,479,511$, and $554 \mathrm{~nm}$. The observed lifetime $\left(\tau_{\text {obs }}\right)$ was $3.8 \mu$ s and the radiative lifetime $\left(\tau_{\mathrm{r}}\right)$ was deduced to be $7.7 \mu \mathrm{s}$. As for complex 2, despite its emission profile being similar to that of $\mathbf{1}$, the quantum yield of 0.14 was significantly inferior to that of $\mathbf{1}$. With an observed lifetime of $4.4 \mu$ s, the radiative lifetime of $\mathbf{2}$ was deduced to be $31.1 \mu \mathrm{s}$, which is about four-times longer than that of $\mathbf{1}$. Accordingly, the nonradiative decay rate constant $\left(k_{\mathrm{nr}}\right)$ is calculated to be $1.30 \times 10^{5}$ and $1.97 \times 10^{5} \mathrm{~s}^{-1}$ for $\mathbf{1}$ and $\mathbf{2}$, respectively. The similarity in $k_{\mathrm{nr}}$ leads to the conclusion that the higher emission quantum yield of $\mathbf{1}$ mainly originates from its shorter radiative lifetime.

To gain insight into the photophysical behavior of the two isomers, density functional theory (DFT) was applied to molecular orbitals involved in the transition (see Figure S3 and S4 of the Supporting Information for the unoccupied and occupied frontier orbitals that are mainly involved in the lowest-lying transition). A description and details of the energy gap of each transition are listed in Table 2. The calculated lowest triplet states for $\mathbf{1}(426 \mathrm{~nm})$ and $\mathbf{2}(425 \mathrm{~nm})$ are close in energy to the $0-0$ onset of phosphorescence obtained experimentally (see Figure 1), if one neglects the 
Table 2: Calculated energy levels of the lowest singlet and triplet states for 1 and 2 .

\begin{tabular}{|c|c|c|c|c|}
\hline & & $\lambda[\mathrm{nm}]$ & Assignment & MLCT $[\%]$ \\
\hline \multirow[t]{7}{*}{1} & $\mathrm{~S}_{1}$ & 398 & HOMO $\rightarrow$ LUMO (+89\%) & \\
\hline & & & $\mathrm{HOMO} \rightarrow \mathrm{LUMO}+1$ (+7\%) & \\
\hline & $\mathrm{T}_{1}$ & 426 & $\mathrm{HOMO} \rightarrow \mathrm{LUMO}+2(+33 \%)$ & 26.6 \\
\hline & & & $\mathrm{HOMO} \rightarrow$ LUMO (20\%) & \\
\hline & & & $\mathrm{HOMO}-1 \rightarrow \mathrm{LUMO}+2(+13 \%)$ & \\
\hline & & & HOMO-2 $\rightarrow$ LUMO + 2 (10\%) & \\
\hline & & & $\mathrm{HOMO} \rightarrow \mathrm{LUMO}+1$ (7\%) & \\
\hline \multirow[t]{5}{*}{2} & $\mathrm{~S}_{1}$ & 400 & $\mathrm{HOMO} \rightarrow \mathrm{LUMO}(+97 \%)$ & \\
\hline & $\mathrm{T}_{1}$ & 425 & HOMO-1 $\rightarrow$ LUMO (+34\%) & 16.9 \\
\hline & & & HOMO-4 $\rightarrow$ LUMO (27\%) & \\
\hline & & & HOMO $-3 \rightarrow$ LUMO (+22\%) & \\
\hline & & & HOMO-2 $\rightarrow$ LUMO (7\%) & \\
\hline
\end{tabular}

associated vibronic and solvation broadening. Therefore, the theoretical level adopted in this work is suitable for interpreting the photophysical properties of the complexes concerned. The lowest-lying electronic transition $\left(\mathrm{S}_{1}\right.$ and $\left.\mathrm{T}_{1}\right)$ is composed of MLCT $\left(\mathrm{d}_{\pi} \rightarrow\right.$ pyridyl fragment) and to a certain extent ILCT (pyrazolyl $\rightarrow$ pyridyl (fppz) fragment) mixed with LLCT (phenyl $\rightarrow$ pyridyl (fppz) fragment; see Figure S3 of the Supporting Information), which is consistent with our original design strategy. Furthermore, the contribution of MLCT, which serves as a key factor in spin-orbit coupling enhancement, is substantial and calculated to be $26.6 \%$ and $16.9 \%$ for $\mathbf{1}$ and $\mathbf{2}$, respectively. From an energetic point of view, it is reasonable to assume that the major component to breaking down the forbidden transition is the $\mathrm{S}_{1}-\mathrm{T}_{1}$ mixing. Accordingly, the phosphorescence radiative decay rate, $k_{\mathrm{p}}$, is given by Equation (1) in which $\alpha$ denotes a

$k_{\mathrm{p}}=\alpha\left|\left\langle\mathrm{S}_{1}\left|\mathscr{H}_{\mathrm{so}}\right| \mathrm{T}_{1}\right\rangle\right|^{2}$

proportional factor and $\mathscr{H}_{\mathrm{so}}$ is the Hamiltonian for the spinorbit coupling. The larger $d_{\pi}$ contribution in $\mathbf{1}$ compared to that in $\mathbf{2}$ should give a larger first-order spin-orbit coupling term and hence a shorter radiative lifetime, which is consistent with the experimental results.

Complex 1 also exhibits a promisingly high quantum yield of 0.45 when it is doped in a wide-gap host, such as 9-(4-tertbutylphenyl)-3,6-bis(triphenylsilyl)-9H-carbazole (CzSi) (see Table 1) or $p$-bis(triphenylsilyl)benzene (UGH2), which have large triplet energies of $3.02 \mathrm{eV}$ and $3.18 \mathrm{eV}$, respectively. ${ }^{[14]}$ Therefore, fabrication of electroluminescent (EL) devices by using 1 was carried out in an attempt to achieve true-blue emission (see the Supporting Information for experimental details).

The configuration of the device is as follows: ITO/ $\alpha-\mathrm{NPD}$ $(\approx 30 \mathrm{~nm}) / \mathrm{TCTA} \quad(30 \mathrm{~nm}) / \mathrm{CzSi} \quad(3 \mathrm{~nm}) / \mathrm{CzSi}$ doped with $10 \mathrm{wt} \%$ of $\mathbf{1}(25 \mathrm{~nm}) / \mathrm{UGH} 2$ doped with $10 \mathrm{wt} \%$ of $\mathbf{1}$ $(3 \mathrm{~nm}) / \mathrm{UGH} 2 \quad(2 \mathrm{~nm}) / \mathrm{TAZ} \quad(50 \mathrm{~nm}) / \mathrm{LiF} \quad(0.5 \mathrm{~nm}) / \mathrm{Al}$ $(150 \mathrm{~nm})$, in which ITO is indium tin oxide, $\alpha$-NPD is $4,4^{\prime}$ bis[ $N$-(1-naphthyl)- $N$-phenylamino]biphenyl, $\quad$ TCTA is $4,4^{\prime}, 4^{\prime \prime}$-tris $(N$-carbazolyl)triphenylamine, and TAZ is 3(biphenyl-4-yl)-4-phenyl-5-(4-tert-butylphenyl)-1,2,4-triazole (the chemical formulae are given in Figure S5 of the Supporting Information). In this device, $\alpha$-NPD and TCTA were used as the hole-transport layer (HTL), while a thin $\mathrm{CzSi}$ layer $(3 \mathrm{~nm})$ was applied for hole transport and for blocking the high-energy triplet excitons (on 1) from migrating to TCTA, which has a lower triplet energy than 1) ${ }^{[14]}$ Double emitting layers (hole-transporting $\mathrm{CzSi}$ and electron-transporting UGH2 doped with $10 \mathrm{wt} \%$ of 1) were used to improve carrier balance between hole and electron injection/ transport to move the exciton formation zone away from the interfaces of both carrier-transport layers. Moreover, a thin UGH2 layer ( $2 \mathrm{~nm}$ ) was applied as the buffer to block highenergy triplet excitons from migrating to TAZ, which also has a lower triplet energy gap than $\mathbf{1}$. Finally, TAZ and LiF were used as the electron-transport layer ${ }^{[15]}$ and the electroninjection layer ${ }^{[16]}$ respectively.

Figure 2 shows representative current-voltage-luminescence characteristics, an EL spectrum, and EL efficiencies of the device. In general, the EL of the device shows a dominant emission from 1, with the main band at $450 \mathrm{~nm}$. The 1931 Commission Internationale de L'Eclairage $(x, y)$ coordinates $\left(\mathrm{CIE}_{x, y}\right)$ calculated from the EL spectrum are $(0.16,0.18)$. The device has a turn-on voltage of $\leq 4 \mathrm{~V}$, an external quantum efficiency of up to $8.5 \%$ photons per electron, a peak power efficiency of $8.5 \mathrm{~lm} \mathrm{~W}^{-1}$, and a maximum brightness of $4000 \mathrm{~cd} \mathrm{~m}^{-2}$ at $16 \mathrm{~V}$. Efficiency roll-off at higher currents that are typical in phosphorescent OLEDs is also observed here $^{[2,4,5]}$ However, at a practical brightness of around $100 \mathrm{~cd} \mathrm{~m}^{-2}$, the efficiency remains high at around $7.5 \%$. Such efficiency characteristics are comparable to those reported for blue-phosphorescent OLEDs. ${ }^{[4,5,14]}$ However, as shown in Figure $2 \mathrm{c}$, the CIE coordinates of the device incorporating $\mathbf{1}$ indicate a substantially bluer emission than for other blue-phosphorescent dopants. For example, devices using the well-known FIrpic dopant usually exhibit CIE coordinates around $(0.17,0.32)$, while devices with other dopants, such as FIr6, FIrtaz, FIrN4, show CIE $y$ values substantially higher than $0.2 \cdot{ }^{[4,5,14]}$

Indeed, to our knowledge, the present device is only the second blue-phosphorescent OLED showing a CIE $y$ value below 0.2 (thus giving true blue) yet still with a respectable EL efficiency. Another example involves the use of the meridional isomer of the tris $(N$-methyl- $N$-phenylbenzimidazolyl) $\mathrm{Ir}^{\mathrm{III}}$ complex, $\left[\mathrm{Ir}(\mathrm{pmb})_{3}\right]$, which exhibits CIE coordinates of $(0.17,0.06)$ but inferior external quantum and peak power efficiencies of only $5.8 \%$ and $1.71 \mathrm{~m} \mathrm{~W}^{-1}$, respectively. ${ }^{[17]}$ Furthermore, such a low CIE $y$ value mainly corresponds to hardly visible near-UV emission $(395 \mathrm{~nm})$, which is not suitable for display or lighting applications.

In conclusion, two isomeric heteroleptic $\mathrm{Ir}^{\mathrm{III}}$ complexes, $\mathbf{1}$ and 2, have been synthesized with the goal of producing authentic blue OLEDs. Salient differences in their photophysical behavior despite their structural isomerism make our approach of prime importance. The lower quantum yield of complex $\mathbf{2}$ relative to that of $\mathbf{1}$ is mainly attributed to a longer radiative lifetime. These results, in combination with a computational DFT approach, confirm that the MLCT contribution in the lowest excited state is the key factor in enhancing room-temperature phosphorescence. Complex $\mathbf{1}$ exhibits a high quantum yield of 0.45 in a doped thin film; the resulting OLED is nearly true blue, shows a maximum 

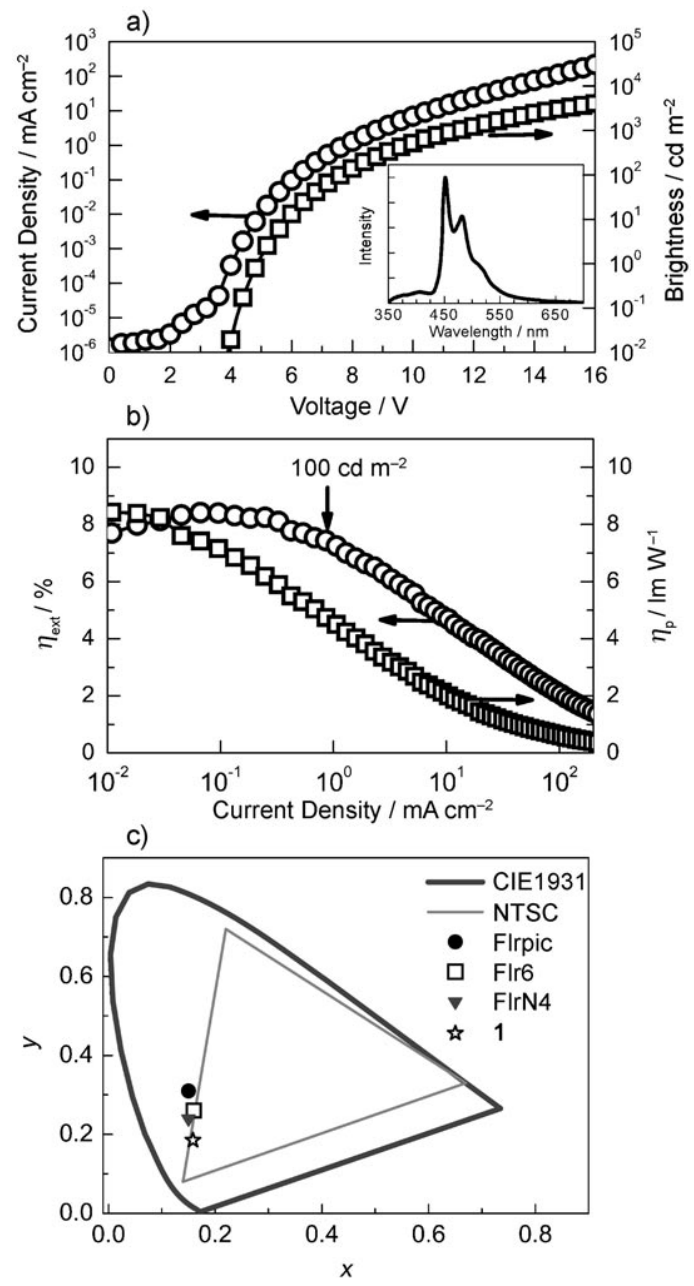

Figure 2. EL characteristics of the device incorporating complex $\mathbf{1}$ : a) Current-voltage-luminescence characteristics; b) external EL quantum efficiency $\left(\eta_{\text {ext }}\right)$ and power efficiency $\left(\eta_{\mathrm{p}}\right)$ versus current density; c) comparison of $\mathrm{CIE}$ coordinates of the EL from several bluephosphorescent dopants. The inset of (a) shows the EL spectrum of the device.

external quantum efficiency of $8.5 \%$ and a CIE of $(0.16,0.18)$. Therefore, a similar conceptual design may equally apply to other heteroleptic IrII $^{\mathrm{III}}$ complexes or even to the homoleptic complexes, if synthetically accessible, to produce a highly emissive, true-blue phosphorescence.

Received: November 21, 2006

Published online: February 26, 2007

Keywords: chelate ligands - density functional calculations . iridium $\cdot$ luminescence $\cdot \mathrm{N}$ ligands

[1] a) H. Yersin, Top. Curr. Chem. 2004, 241, 1; b) E. Holder, B. M. W. Langeveld, U. S. Schubert, Adv. Mater. 2005, 17, 1109; c) P.-T. Chou, Y. Chi, Eur. J. Inorg. Chem. 2006, 3319; d) P.-T. Chou, Y. Chi, Chem. Eur. J. 2007, 13, 380.

[2] a) M. A. Baldo, D. F. O'Brien, Y. You, A. Shoustikov, S. Sibley, M. E. Thompson, S. R. Forrest, Nature 1998, 395, 151; b) S. Lamansky, P. Djurovich, D. Murphy, F. Abdel-Razzaq, H.-E.
Lee, C. Adachi, P. E. Burrows, S. R. Forrest, M. E. Thompson, J. Am. Chem. Soc. 2001, 123, 4304.

[3] a) P. Coppo, E. A. Plummer, L. De Cola, Chem. Commun. 2004, 1774; b) M. K. Nazeeruddin, R. Humphry-Baker, D. Berner, S. Rivier, L. Zuppiroli, M. Graetzel, J. Am. Chem. Soc. 2003, 125, 8790 ; c) C. S. K. Mak, A. Hayer, S. I. Pascu, S. E. Watkins, A. B. Holmes, A. Koehler, R. H. Friend, Chem. Commun. 2005, 4708; d) Y. You, S. Y. Park, J. Am. Chem. Soc. 2005, 127, 12438; e) R. Ragni, E. A. Plummer, K. Brunner, J. W. Hofstraat, F. Babudri, G. M. Farinola, F. Naso, L. De Cola, J. Mater. Chem. 2006, 16, 1161.

[4] a) R. J. Holmes, S. R. Forrest, Y.-J. Tung, R. C. Kwong, J. J. Brown, S. Garon, M. E. Thompson, Appl. Phys. Lett. 2003, 82, 2422; b) S. Tokito, T. Iijima, Y. Suzuri, H. Kita, T. Tsuzuki, F. Sato, Appl. Phys. Lett. 2003, 83, 569.

[5] S.-J. Yeh, W.-C. Wu, C.-T. Chen, Y.-H. Song, Y. Chi, M.-H. Ho, S.-F. Hsu, C.-H. Chen, Adv. Mater. 2005, 17, 285.

[6] Y.-Y. Lyu, Y. Byun, O. Kwon, E. Han, W. S. Jeon, R. R. Das, K. Char, J. Phys. Chem. B 2006, 110, 10303.

[7] a) J. Li, P. I. Djurovich, B. D. Alleyne, M. Yousufuddin, N. N. Ho, J. C. Thomas, J. C. Peters, R. Bau, M. E. Thompson, Inorg. Chem. 2005, 44, 1713; b) T. Yutaka, S. Obara, S. Ogawa, K. Nozaki, N. Ikeda, T. Ohno, Y. Ishii, K. Sakai, M. Haga, Inorg. Chem. 2005, 44, 4737.

[8] Y.-L. Tung, L.-S. Chen, Y. Chi, P.-T. Chou, Y.-M. Cheng, E. Y. Li, G.-H. Lee, C.-F. Shu, F.-I. Wu, A. J. Carty, Adv. Funct. Mater. 2006, 16, 1615.

[9] a) J.-K. Yu, Y.-H. Hu, Y.-M. Cheng, P.-T. Chou, S.-M. Peng, G.H. Lee, A. J. Carty, Y.-L. Tung, S.-W. Lee, Y. Chi, C.-S. Liu, Chem. Eur. J. 2004, 10, 6255; b) S. Zalis, I. R. Farrell, A. Vlcek, J. Am. Chem. Soc. 2003, 125, 4580 .

[10] a) Y.-S. Yeh, Y.-M. Cheng, P.-T. Chou, G.-H. Lee, C.-H. Yang, Y. Chi, C.-F. Shu, C.-H. Wang, ChemPhysChem 2006, 7, 2294; b) C.H. Yang, S.-W. Li, Y. Chi, Y.-M. Cheng, Y.-S. Yeh, P.-T. Chou, G.H. Lee, C.-H. Wang, C.-F. Shu, Inorg. Chem. 2005, 44, 7770.

[11] S.-C. Lo, C. P. Shipley, R. N. Bera, R. E. Harding, A. R. Cowley, P. L. Burn, I. D. W. Samuel, Chem. Mater. 2006, 18, 5119.

[12] Crystal data for 1: $\mathrm{C}_{29.50} \mathrm{H}_{15.75} \mathrm{~F}_{8} \mathrm{IrN}_{7.25}, M_{\mathrm{r}}=815.94$, orthorhombic, space group Pbca, $T=150 \mathrm{~K}, a=17.7805(3), b=17.7519(3), c=$ 35.9198(6) $\AA, V=11337.6(3) \AA^{3}, Z=16, \mu\left(\mathrm{Mo}_{\mathrm{K} \alpha}\right)=4.799 \mathrm{~mm}^{-1}$; 27243 reflections were collected of which 9959 were unique $\left(R_{\text {int }}=0.1349\right)$, final $R_{1}[I>2 \sigma(I)]=0.0694, \quad w R_{2}($ all data $)=$ 0.1661. Crystal data for 2: $\mathrm{C}_{30} \mathrm{H}_{20} \mathrm{~F}_{8} \mathrm{IrN}_{7} \mathrm{O}, M_{\mathrm{r}}=838.73$, triclinic, space group $P \overline{1}, T=150 \mathrm{~K}, a=10.8152(3), b=14.8498(4), c=$ 20.6391(5) $\AA, \alpha=85.0088(15), \beta=75.4553(14), \gamma=79.6901(14)^{\circ}$, $V=3153.60(14) \AA^{3}, Z=4, \mu\left(\mathrm{Mo}_{\mathrm{K} \alpha}\right)=4.318 \mathrm{~mm}^{-1} ; 37324$ reflections were collected of which 11120 were unique $\left(R_{\text {int }}=0.0715\right)$, final $R_{1}[I>2 \sigma(I)]=0.0470, \quad w R_{2}($ all data $)=0.1318$. CCDC628026 (1) and CCDC-628027 (2) contain the supplementary crystallographic data for this paper. These data can be obtained free of charge from The Cambridge Crystallographic Data Centre via www.ccdc.cam.ac.uk/data_request/cif.

[13] a) Y.-H. Song, S.-J. Yeh, C.-T. Chen, Y. Chi, C.-S. Liu, J.-K. Yu, Y.-H. Hu, P.-T. Chou, S.-M. Peng, G.-H. Lee, Adv. Funct. Mater. 2004, 14, 1221; b) F.-M. Hwang, H.-Y. Chen, P.-S. Chen, C.-S. Liu, Y. Chi, C.-F. Shu, F.-I. Wu, P.-T. Chou, S.-M. Peng, G.-H. Lee, Inorg. Chem. 2005, 44, 1344.

[14] a) M.-H. Tsai, H.-W. Lin, H.-C. Su, C.-C. Wu, F.-C. Fang, Y.-L. Liao, K.-T. Wong, C.-I. Wu, Adv. Mater. 2006, 18, 1216; b) R. J. Holmes, B. W. D'Andrade, S. R. Forrest, X. Ren, J. Li, M. E. Thompson, Appl. Phys. Lett. 2003, 83, 3818.

[15] J. Kido, M. Kimura, K. Nagai, Science 1995, 267, 1332.

[16] L. S. Hung, C. W. Tang, M. G. Mason, Appl. Phys. Lett. 1997, 70, 152.

[17] R. J. Holmes, S. R. Forrest, T. Sajoto, A. Tamayo, P. I. Djurovich, M. E. Thompson, J. Brooks, Y.-J. Tung, B. W. D'Andrade, M. S. Weaver, R. C. Kwong, J. J. Brown, Appl. Phys. Lett. 2005, 87, 243507. 